\title{
Pedicularis condensata Türüne ait Anatomi ve Aktivite Çalışmaları
}

\author{
Burcu Şen Utsukarçi, Bahar Gürdal, Turgut Taşkın, Mayram Tüysüz, Çağla Bozkurt Güzel, Selin Tufan, Afife Mat
}

Öz

Pedicularis L. cinsi Türkiye'de 2 tanesi endemik olmak üzere 11 tür ile temsil edilmektedir. Ülkemizde sormuk, sorma, sormuk otu isimleri ile bilinmektedir. Halk arasında kullanımı pek bilinmemek ile birlikte Doğu Anadolu'da çiçeklerindeki balözü nedeni ile gıda olarak kullanımı kayıtlıdır. Bugüne kadar Pedicularis condensata Bieb. türü üzerinde yapılan çalışmalar incelendiğinde, saç boyası araştırma çalışmaları sırasında alınan patentlerde yer aldığı görülmektedir. Ayrıca Pedicularis (Kesgerotu) türleri üzerinde çeşitli izolasyon ve aktivite çalışmaları literatürde mevcuttur. Bu türlerin iridoit ve feniletanoit bileşikleri taşıdıkları görülmektedir. İridoitler antioksidan, antimikrobiyal, antienflamatuvar, immunomodülatör vb. etki gösterirken feniletanoit glikozitleri ise hepatoprotektif, antioksidan, antienflamatuvar, antibakteriyal, antiviral, vb. etkilere sahiptir. Pedicularis condensata bitkisinin izolasyon çalışmaları göz önüne alındığında bu etkilerden bazılarını göstermesi mümkündür. Daha önce bu tür üzerinde anatomi ve aktivite çalışması yapılmamıştır. $\mathrm{Bu}$ çalışma ile türün anatomik özellikleri ve farklı yöntemler ile farklı çözücüler kullanılarak elde edilmiş ekstrelerinin aktivite testlerinin sonuçları sunulmuştur. Trabzon'dan toplanan bitkinin toprak üstü kısımlarından maserasyon ve Soxhlet cihazında sürekli ekstraksiyon ile elde edilen çeşitli ekstrelerin (hekzan, diklorometan, metanol ekstreleri; metanol maseratı) sahip olduğu antioksidan ve antimikrobiyal aktiviteleri araştırılmıştır.

Anahtar kelimeler: Pedicularis condensata, bitki anatomisi, antimikrobiyal, antioksidan
Burcu Şen Utsukarci, Selin Tufan, Afife Mat

İstanbul Üniversitesi, Eczacıllk Fakültesi, Farmakognozi Anabilim Dalı

Bahar Gürdal

İstanbul Üniversitesi, Eczacılık Fakültesi, Farmasötik Botanik Anabilim Dalı

Turgut Taşkın

Marmara Üniversitesi, Eczacılık Fakültesi, Farmakognozi Anabilim Dalı

Mayram Tüysüz, Çağla Bozkurt Güzel

İstanbul Üniversitesi, Eczacılık Fakültesi, Farmasötik Mikrobiyoloji Anabilim Dalı

Sorumlu Yazar:

Burcu Şen Utsukarçi

e-posta:burcusn@gmail.com

Submitted / Gönderilme: 01.02.2017 Revised / Düzeltme: 22.02.2017

Accepted / Kabul: $\quad 26.02 .2017$

\section{Giriş}

Pedicularis L. cinsi Türkiyede 2 tanesi endemik olmak üzere 11 tür ile temsil edilmektedir $(1,2)$. Ülkemizde sormuk, sorma, sormuk otu isimleri ile bilinmektedir. Halk arasında kullanımı pek bilinmemek ile birlikte Doğu Anadolu’da çiçeklerindeki balözü nedeni ile gıda olarak kullanımı kayıtlıdır (3, 4). 2007 yılında yapılan bir çalışmada P. armata metanol ekstresinden izole edilen biri yeni olmak üzere 7 bileşiğin antibakteriyal etkileri saptanmıştır. İlk kez izole edilen bileşik "armaoside" ismi ile tayin edilmiş ve ilk kez sitrusin B bileşiğinin tam konfigürasyonu belirlenmesinin yanında izole edilen bileşiklerin içinde en güçlü etkiyi 8-epiloganik asit ve okubin bileşiklerinin gösterdiği saptanmıştır (5). Ayrica $P$. palustris, $P$. silvatica ve $P$. lapponica türlerinden iridoit eldesi çalışmaları da literatürde mevcuttur (6). Pedicularis kansuensis ile yapılan iki çalışma sonucunda türden 1 yeni iridoit ve 1 yeni iridoit glikozidi, 1 yeni triterpenoit ve 2 yeni fenilpropanoit glikozidi dahil olmak üzere 23 bileşik izole edilmiştir. Çalışmalardan birinde ayrıca elde edilen 3 bileşiğin Hela ve Hep-6 hücreleri 
üzerindeki etkisi de araştırılmış ve oldukça olumlu sonuçlar elde edilmiştir. İridoit izolasyonunun yapıldığı çalışmada ise 10 iridoit ve türevi bileşikler ile yapılan antimikrobiyal test sonucunda bu bileşiklerden 9'unun Bacillus subtilis, Escherichia coli ve Staphylococcus aureus bakterilerine karşı etki gösterdiği belirlenmiştir. Bu tür ile başka bir Pedicularis türü (P. resupinata) üzerinde izolasyon çalısması yapılarak glikozitleri araştırılmıştır. Yine iki Pedicularis türünden (P. kansuensis ve $P$. longiflora) kapiler elektroforez ile fenilpropanoit glikozitlerin izolasyonu ve yapı tayinleri gerçekleştirilmiştir (7-10). 1997 yılında P. striata Pall. türü üzerinde yapılan bir araştırmada, izole edilen 3 feniletanoit bileşiğinin (verbaskozit, izoverbaskozit ve verbaskozidin yarı sentetik türevi olan permetilverbaskozit) antioksidatif ve şelatlama aktivitelerinin incelenerek permetilverbaskozit bu aktivitelerin hiçbirini göstermezken izoverbaskozidin şelatlama aktivitesinin verbaskozidinkinden 2 kat güçlü olduğu belirlenmiştir (11). Aynı ekibin yayınladığı diğer bir çalışmada $P$. striata türünden elde edilen izoverbaskozit, verbaskozit, ekinakozit ve pedicularioside A; P. lasiophrys'tan elde edilen sistanozit $\mathrm{D}$ bileşiklerinin ve ayrıca verbaskozidin yarı sentetik türevi permetilverbaskozit bileşiğinin süperoksit ve onun antioksidan etkisi üzerine süpürücü aktivitesi test edilmiş ve bileşiklerin yapı-etki ilişkileri ortaya konmuştur (12). P. alashanica Maxim türünden elde edilen lökoseptozit A ve martinozit bileşikleri ile $P$. striata Pall subsp. arachnoides Franch Tsoong türünden elde edilen verbaskozit; pedikulariozit $\mathrm{A}, \mathrm{M}$ ve $\mathrm{N}$ bileşiklerine ait süperoksit anyon ve hidroksil radikallerinin süpürücü etkisi çalışılmış ve bu etkinin, bileşiğin yapısındaki fenolik hidroksil gruplarının sayısına bağlı olduğu saptanmıştır (13). Bunlardan başka 3 Pedicularis türü ( $P$. condensata, P. sibthorpii Boiss. ve P. wilhelmsiana Fisch ex. M.Bieb.) ile izole feniletanoit glikozitleri üzerinde yapılan çalışmada $P$. condensata'dan verbaskozit ve 2'-O-asetilverbaskozit; diğer iki Pedicularis türünden ise sadece verbaskozit izole edilebilmiştir (14). Bu türlerden $P$. sibthorpii ve $P$. wilhelmsiana üzerinde yapılan bir başka araştırmada ise bu türlerden hazırlanan metanol ekstrelerinin antioksidan etkisi (DPPH yöntemi ile), total fenol ve total flavanoit içerikleri saptanmıştır (15). Aynı merkezde bu iki türün toprak üstü kısımlarının Soxhlet cihazında sürekli ekstraksiyona tabi tutularak elde edilen n-hekzan, diklorometan ve metanol ekstrelerinin antioksidan ve antimikrobiyal aktiviteleri araştııılmıştır (16). Aynı grup çalışmalarını devam ettirerek $P$. sibthorpii türünün fitokimyasını ve biyoaktivitesini yayınlamıştır. Türün toprak üstü kısımlarından hazırlanan metanol ekstresinin DPPH yöntemi ile antioksidan testinde ve agar oluk difüzyon yöntemi ile yapılan antimikrobiyal testte aktif olduğunun belirlenmesinin yanında brine shrimp lethality yönteminde herhangi bir toksisiteye rastlanmamıştır. Katı faz ekstraksiyonu ve preparatif yüksek performanslı sivı kromatografisinin bir kombinasyonu ile bu ekstrede 3 feniletanoit (verbaskozit, martinozit ve izomartinozit), 1 iridoit (okubin), 1 flavonoit (luteolin7-O- $\beta$ - $D$-glukopiranozit) ve mannitol tayin edilmiştir (17). Akdemir ve ark., $P$. condensata türünün toprak üstü kısımlarından hazırladıkları metanol ekstresinden bir yeni iridoit bileşiği (6-O-asetilokubin) dışında 5 bilinen iridoit (okubin, 8-epiloganin, mussaenozit, şanzizit metil esteri); 2 feniletanoit glikozitleri (verbaskozit ve ekinakozit) izole etmişlerdir (18).

İridoit glikozitleri nöroprotektif, antikanser, antienflamatuvar, immunomodülatör, antioksidan, antimikrobiyal, hipoglisemik, hipolipidemik, yara iyileştirici, koleretik, antialerjik, anksiyolitik etki göstermektedir (19). Feniletanoit glikozitlerinin ise hepatoprotektif, antioksidan, sitotoksik, antienflamatuvar, a-glukozidaz inhibitör, nöroprotektif, antibakteriyal, antiviral, immunomodulatör etki gösterdiği çeşitli çalışmalar ile kanıtlanmıştır (20). Bu türler taşıdıkları bileşikler açısından değerlendirildiğinde bu türlerin bileşiklerin sahip oldukları etkileri de meydana getirme olasılıkları açıktır. Daha önce Pedicularis condensata türünün anatomi ve aktivitesi üzerinde herhangi bir araştırma kayıtlara geçmemiştir. Bu çalışma ile kırk bitotu ismi ile anılan Pedicularis condensata anatomik çalışmasının yanı sıra farklı yöntemler ile farklı çözücüler kullanılarak elde edilmiş ekstrelerinin aktivite testlerinin sonuçları sunulmuştur. Trabzon'dan toplanan bitkinin toprak üstü kısımlarından maserasyon ve Soxhlet cihazında sürekli ekstraksiyon ile elde edilen çeşitli ekstrelerin (hekzan, diklorometan, metanol ekstreleri; metanol maseratı) sahip olduğu antioksidan ve antimikrobiyal aktiviteler incelenmiştir.

\section{Gereç ve Yöntem:}

Bitki Materyali: Pedicularis condensata türü Trabzon Maçkađdan toplanarak Araş. Gör. Dr. Bahar Gürdal tarafından teşhis edilmiştir. Referans örneği İstanbul Üniversitesi Eczacılık Fakültesi Herbaryumu’nda ISTE 110344 numarası ile saklanmaktadır.

\section{Anatomik Çalışma:}

Toplanan örneklerin yaprak ve gövde kısımları anatomik çalışmalar yapılması için \%70'lik etanolde fikse edilerek saklanmıştır. Gövde ile yaprağın enine ve yüzeysel kesitleri 
el ile alınmıştır. Anatomik kesitler Sartur boyama tekniği kullanılarak incelenmiştir. Örneklerin anatomik fotoğrafları Olympus BX-53 1şık mikroskobunda, Olympus E330 dijital renkli kamera ile çekilmiştir.

Ekstraksiyon: Kurutulmuş ve toz edilmiş toprak üstü kısımlarından 3 farklı yol izlenerek ekstreleri elde edilmiştir. İlk olarak; drogun üçte biri Soxhlet cihazında sırasıyla hekzan (PHS), diklorometan (PDS) ve metanol (PMS) ile 1 gece maserasyonun ardından tüketilmiştir. Daha sonra diğer üçte bir kısım ayrı ayrı ve sırasıyla hekzan (PHMs), diklorometan (PDMs) ve metanol (PMMs) ile 24'er saat masere edilmiştir. En son olarak drogun kalan miktarı metanol (PMM) ile 24 saat boyunca masere edilmiştir. Elde edilen tüm ekstreler vakum altında yoğunlaştırılmış ve buzdolabında $\left(+4^{\circ} \mathrm{C}\right)$ saklanmıştır.

\section{Antioksidan Aktivite Tayini:}

DPPH Radikali Giderme Aktivite Tayini:

Bitkiden elde edilen farklı ekstrelerin serbest radikal yakalama etkinliği 2,2-difenil-1-pikrilhidrazil (DPPH) radikali kullanılarak tayin edilmiştir (21).

Farklı konsantrasyonlarda hazırlanan ekstrelerden ve standart çözeltilerden (askorbik asit ve BHT) 0,1'er mL alınarak, 3,9 mL 0,1 mM DPPH çözeltisi ilave edilmiştir. DPPH çözeltisi ilave edilen ekstreler ve standart çözeltiler $1 \mathrm{dk}$. vortekslendikten sonra oda koşullarında ve karanlıkta $30 \mathrm{dk}$. bekletilmiştir. Daha sonra karışımın absorbansı 517 nm'de UV-spektrofotometrede (Shimadzu 1800) referansa karşı ölçülmüştür. Deney üç kez tekrarlanarak ortalaması alınmıştır. IC50 değeri hesaplanmadan önce \% DPPH radikali giderme kapasitesi aşağıda verilen formül ile hesaplanmıştır:

$\% \mathrm{DPPH}$ radikali giderme kapasitesi $=[(\mathrm{A} 0-\mathrm{A} 1) / \mathrm{A} 0] \times 100]$

A0 : Kontrol çözeltisinin absorbansı,

\section{A1 : Bitki ekstreleri ve standart çözeltilerin absorbansı}

Başlangıç DPPH• derişiminde \% 50 azalmaya neden olan ekstre ve standart madde konsantrasyonu IC50 olarak tanımlanmıştır. Bu değer çalışılan konsantrasyonlara karşı \% serbest radikal giderme aktivite değerlerinin yerleştirilmesi ile elde edilen doğru denklemi kullanılarak hesaplanmış ve sonuçlar IC $50=\mathrm{mg} / \mathrm{mL}$ olarak verilmiştir.

\section{ABTS Katyon Radikali Giderme Aktivite Tayini:}

ABTS katyon radikali, 2,2-azinobis-(3-etilbenzotiozin-6sulfonik asit) amonyum tuzu (ABTS2-) nun peroksodisülfatla oksidasyonu sonucu meydana gelmiştir. 7 mM ABTS amonyum tuzu suda çözülmüş ve 2,45 $\mathrm{mM}$ potasyum peroksodisülfatla reaksiyona sokularak hazırlanan ABTS•+ stok çözeltisi oda sıcaklığında koyu mavi bir renk meydana gelmesini sağlamak için 12 - 16 saat bekletilmiştir. Deney gününde, ABTS•+ stok çözeltisi, 734 nm’de absorbansı $0,70( \pm 0,02)$ olacak şekilde metanol ile seyreltilerek ABTS•+çalışma çözeltisi hazırlanmıştır. Farklı konsantrasyonlarda hazırlanan ekstrelerden ve standart çözeltiden (askorbik asit) 40 ’ar $\mu \mathrm{L}$ alınarak, $3960 \mu \mathrm{L}$ ABTS•+ çalışma çözeltisi ilave edildikten sonra renkte meydana gelen azalma spektrofotometrik olarak 734 nm'de referansa karşı 6. dk.da ölçülmüştür. Deney üç kez tekrarlanarak ortalaması alınmıştır. (22) \% ABTS katyon radikalini giderici aktivite aşağıda verilen formül ile hesaplanmıştır:

$\%$ ABTS katyon radikalini giderici aktivite $=[(\mathrm{A} 0-\mathrm{A} 1) /$ $\mathrm{A} 0] \times 100]$

A0 : Kontrol reaksiyonunun absorbansı

A1 : Bitki ekstreleri ve standart çözeltilerin absorbansı

Başlangıç ABTS•+ katyon radikali derişiminde $\% 50$ azalmaya neden olan ekstre ve standart madde konsantrasyonu IC50 olarak tanımlanarak sonuçlar IC $50=\mathrm{mg} / \mathrm{mL}$ olarak verilmiştir.

Demir (III) iyonu indirgeme antioksidan gücü tayini (FRAP):

FRAP ayırac1, $25 \mathrm{~mL} 300 \mathrm{mM}$ asetat tamponu (pH 3,6), 2,5 mL TPTZ çözeltisi (10 mM TPTZ’nin 40 mM HCI'deki çözeltisi) ve $2,5 \mathrm{~mL} 20 \mathrm{mM}$ FeCI3.6H2O'nin karıştırılması ile hazırlandıktan sonra $37 \mathrm{oC}$ de $30 \mathrm{dk}$. bekletilmiştir. FRAP ayıracının 3,8 mL'si $0,2 \mathrm{~mL}$ ekstre ile karıştırılarak, ekstre yerine distile su eklenip hazırlanan referansa karşı absorbans artışı 4. dakikada 593 nm’de ölçülmüsstür. Ekstrelerin 593 nm'deki absorbans değerleri, FeSO4.7H2O ile hazırlanan kalibrasyon grafiğine (Abs. $=1,668 \mathrm{FeSO} 4(\mu \mathrm{M})-0,11674$ (R2: 0,9982) ait değerlerle karşılaştırılmak suretiyle, FRAP değeri $\mu \mathrm{M} \mathrm{FeSO} 4 / \mathrm{mg}$ ekstre olarak ifade edilmiştir (23).

\section{Antimikrobiyal Aktivite Tayini:}

Hazırlanan ekstrelerin antimikrobiyal aktiviteleri Staphylococcus aureus ATCC 6538, Staphylococcus epidermidis ATCC 12228, Enterococcus faecalis ATCC 29212, Escherichia coli ATCC 8739, Klebsiella pneumoniae ATCC 4352, Pseudomonas aeruginosa ATCC 27853, Proteus mirabilis ATCC 14153 ve Candida albicans ATCC 10231 standart suşlarına karşı Minumum İnhibitör Konsantrasyonu (MİK) değerleri, Clinical Laboratory Standards Institute (CLSI) kriterleri esas alınarak mikrodilüsyon yöntemiyle belirlenmiştir $(24,25)$. 


\section{Bulgular}

\section{Anatomik Çalışmalar:}

Yaprak anatomisi; Enine kesitte üst ve alt epidermis tek sıralı, oval hücrelerden oluşmuştur. En dişta ince kutikula tabakası yer alır. Stoma sadece alt epidermiste bulunur, hipostomatik yaprak ve stoma tipi anomositiktir. Yaprağın alt yüzeyinde yoğun olarak çok hücreli basit örtü tüyleri, üst yüzeyde ise özellikle orta damar bölgesinde ve seyrek olarak bulunur. İletim demeti kollateral tiptedir. Mezofil tabakada bir sıra palisad, 2-3 sıra sünger parankiması yer alır, dorsiventral yaprak.

Yaprak orta damarı enine kesiti görüntüsü Şekil 1'de yer almaktadir.

Gövde anatomisi; Parankimatik öz bölgesi parçalanmıştır, iç boş gövde. En dışta kalın kutikula, altında ovoid epidermis yer alır. Çok hücreli basit örtü tüyleri görülmektedir. Kollenkima 4-5 sralıdır. İletim demeti kollateral tiptedir ve demetler gövdeyi çepeçevre kuşatmıştır.

Gövde enine kesiti görüntüsü Şekil 2'de yer almaktadır.

\section{Antioksidan aktivite:}

Bitkilerin antioksidan aktivitelerini değerlendirmek için tek bir test yapmak, doğru sonucu vermez çünkü bitki ekstraktının antioksidan aktivitesi, test sistemi ve ekstrenin bileşimi gibi birçok faktörden etkilenmektedir. $\mathrm{Bu}$ nedenle ekstrelerin aktivitelerini birden fazla antioksidan aktivite yöntemleri kullanılarak ölçülmesi oldukça önemlidir (26). Bundan dolayı bu çalışmada, P. condensata bitkisinden elde edilen farklı ekstrelerin antioksidan aktivitesi, DPPH, FRAP ve ABTS olmak üzere üç farklı antioksidan yöntemi kullanılarak ölçülmüştür. P. condensata türünden elde edilen farklı ekstrelerin antioksidan aktiviteleri Tablo 1 ve Şekil 3’de gösterilmiştir.

DPPH yöntemi genellikle polar bileşiklerin aktivitesini ölçmekte sıklıkla kullanılan bir yöntemdir. Bu çalışmada, ekstrelerin ve standartların DPPH radikali giderme aktiviteleri aşağıda belirtilen sıra düzeninde tespit edilmiştir. Pozitif control olarak askorbik asit ve BHT kullanılmıştır.

\section{A. asit $>$ BHT $>$ PMMs $>$ PMM $>$ PMS $>$ PDS $>$ PDMs $>$ PHMs $>$ PHS}

IC50 değerleri ile antioksidan aktivite arasında ters bir orantının olduğu göz önüne alındığında, bitkinin sıralı maserasyonu sırasında methanol ile kazanılmış ekstresinin (PMMs) diğer ekstrelerden daha güçlü, fakat standart bileşiklerden ise daha düşük $\mathrm{DPPH}$ radikali süpürücü aktivite gösterdiği saptanmıştır.

ABTS katyon radikali süpürücü aktivite yöntemi, genellikle bitkilerin antioksidan aktivitesini ölçmekte kullanılan bir

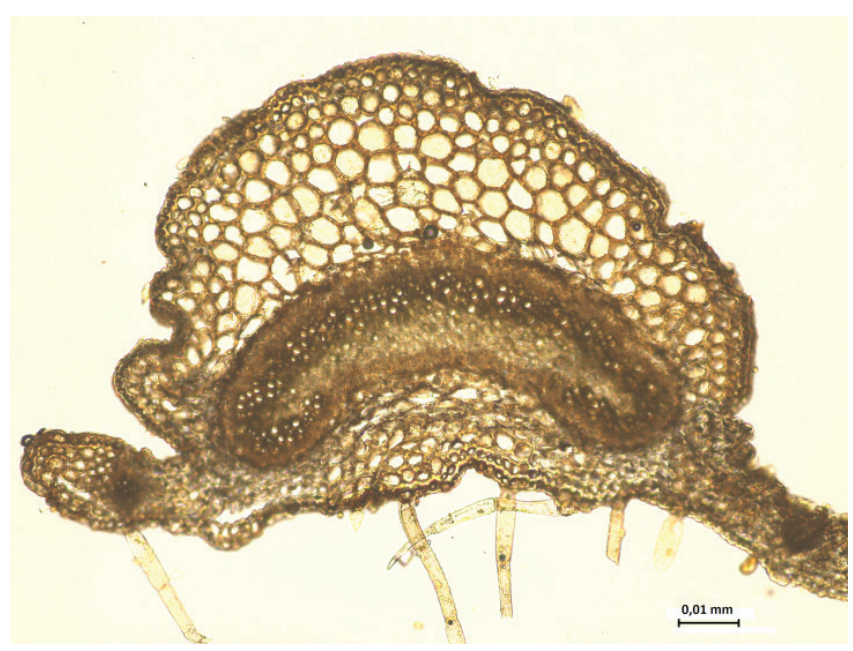

Şekil 1: P. condensata bitkisinin yaprak orta damarı enine kesiti

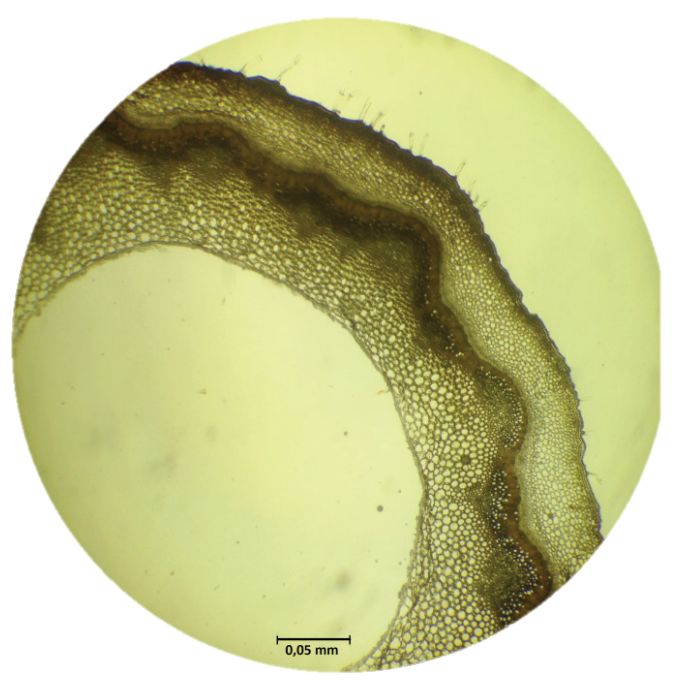

Şekil 2: $P$. condensata bitkisinin gövde enine kesiti

yöntemdir. Bu çalımada ekstrelerin ABTS radikali süpürücü aktiviteleri askorbik asit ile karşılaştırılıp aşağıdaki sıra düzeni tespit edilmiştir.

\section{asit $>$ PMM $>$ PMMs $>$ PMS $>$ PDS $>$ PDMs $>$ PHMs $>$ PHS}

Elde edilen sonuçlar değerlendirildiğinde PMM ekstresinin askorbik asitten düşük; diğer ekstrelerden ise daha güçlü ABTS katyon radikali süpürücü aktivite göstediği saptanmıştır.

Antioksidan bileşiklerin demir (III) iyonlarını indirgeme kabiliyeti, onların önemli bir özelliğidir. Bundan dolayı bu çalışmada P. condensata bitkisinden elde edilen ekstrelerin demir (III) iyonu indirgeme antioksidan kapasiteleri incelendiğinde ekstrelerin 
Tablo 1: $P$. condensata bitkisinden elde edilen farklı ekstrelerin antioksidan aktivitesi

\begin{tabular}{|c|c|c|c|}
\hline Ekstreler & $\mathrm{DPPH}\left(\mathrm{IC}_{50}: \mathrm{mg} / \mathrm{mL}\right)$ & $\operatorname{ABTS}\left(\mathrm{IC}_{50}: \mathrm{mg} / \mathrm{mL}\right)$ & FRAP $(\mu \mathrm{M} \mathrm{FeSO} / \mathrm{mg}$ ekstre $)$ \\
\hline PHMs & $39,095 \pm 0,74$ & $14,805 \pm 0,98$ & $0,493 \pm 0,002$ \\
\hline PHS & $48,365 \pm 0,94$ & $22,265 \pm 0,05$ & $0,572 \pm 0,004$ \\
\hline PDMs & $23,293 \pm 0,67$ & $8,255 \pm 0,67$ & $1,232 \pm 0,09$ \\
\hline PDS & $10,87 \pm 0,51$ & $4,963 \pm 0,08$ & $1,630 \pm 0,04$ \\
\hline PMMs & $1,087 \pm 0,06$ & $2,82 \pm 0,07$ & $2,121 \pm 0,001$ \\
\hline PMS & $2,033 \pm 0,002$ & $3,63 \pm 0,27$ & $1,962 \pm 0,013$ \\
\hline PMM & $2,016 \pm 0,117$ & $2,11 \pm 0,19$ & $2,045 \pm 0,03$ \\
\hline BHT & $0,323 \pm 0,03$ & - & - \\
\hline A. asit & $0,093 \pm 0,006$ & $0,503 \pm 0,02$ & - \\
\hline
\end{tabular}
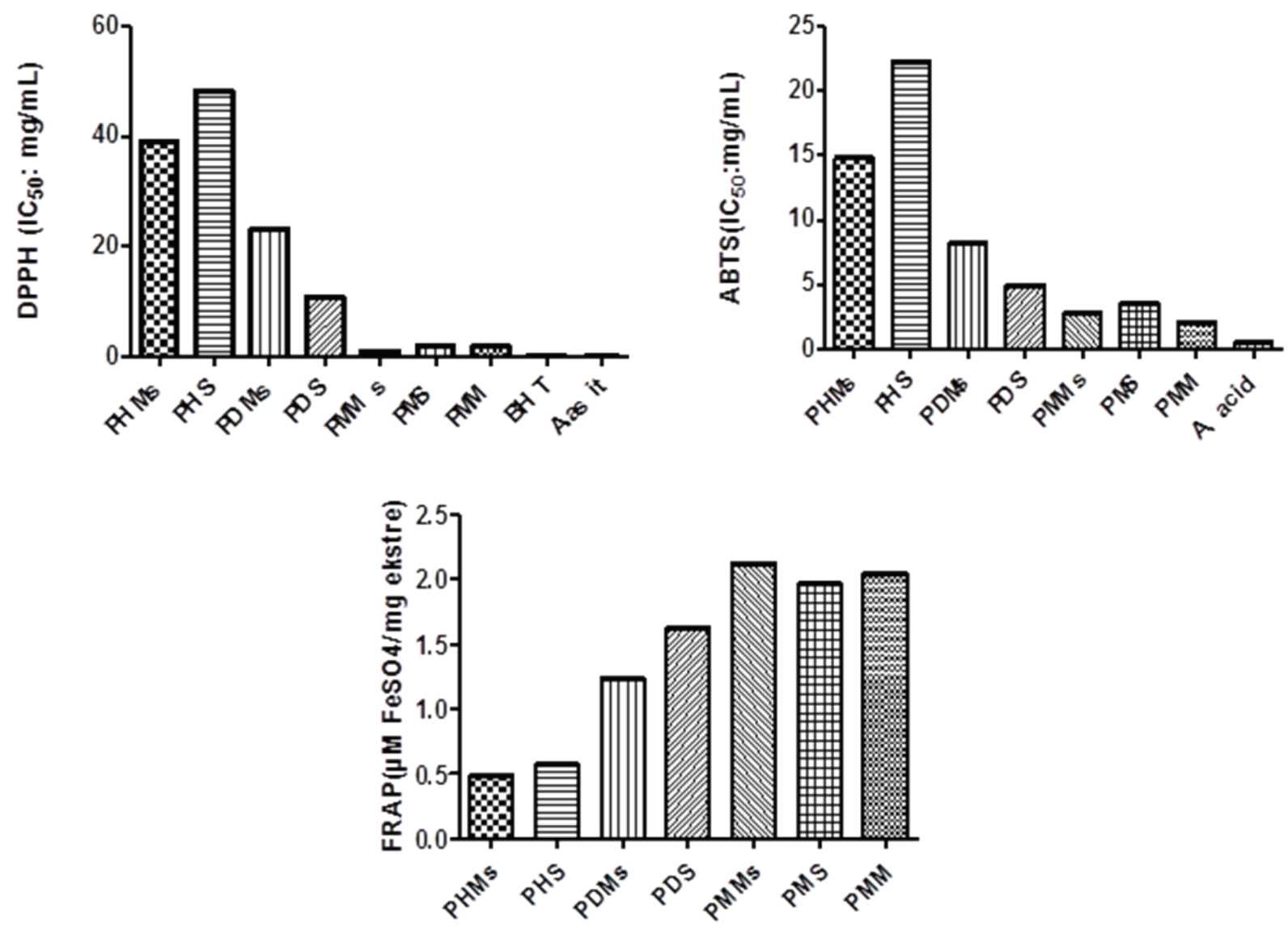

Şekil 3: $P$. condensata bitkisinin farklı ekstrelerinin antioksidan aktivitesi 
Tablo2: $P$. condensata bitkisinin farklı ekstrelerine ait in vitro antimikrobiyal aktivitesi

\begin{tabular}{|c|c|c|c|c|c|c|c|c|}
\hline & \multicolumn{8}{|c|}{ Minumum İnhibitör Konsantrasyonları (MİK) ( $\mu \mathrm{g} / \mathrm{mL})$} \\
\hline & S. aureus & S. epidermidis & E. faecalis & E. coli & K. pneumoniae & P. aeruginosa & P. mirabilis & C. albicans \\
\hline PHMs & - & 1250 & - & - & 2500 & - & - & - \\
\hline PHS & - & - & - & - & - & - & - & - \\
\hline PDMs & - & - & - & - & - & - & - & - \\
\hline PDS & - & - & - & - & - & - & - & - \\
\hline PMMs & - & 1250 & - & - & 2500 & - & - & - \\
\hline PMS & - & - & - & - & - & - & - & - \\
\hline PMM & - & 1250 & - & - & 2500 & - & - & - \\
\hline Referans & ${ }^{\star} 0,25$ & ${ }^{*} 0,5$ & $\star 2$ & ${ }^{\star} 0,03$ & ${ }^{*} 0,03$ & ${ }^{*} 0,5$ & ${ }^{*} 0,06$ & $* * 1$ \\
\hline
\end{tabular}

Referans: ${ }^{\star}$ Siprofiloksasin, ${ }^{* *}$ Amfoterisin B

(-): Herhangi bir etki tespit edilememiştir

aktiviteleri aşağıda belirtilen sıra düzeninde saptanmıştır. $\mathrm{PMMs}>\mathrm{PMM}>\mathrm{PMS}>\mathrm{PDS}>\mathrm{PDMs}>\mathrm{PHS}>\mathrm{PHMs}$

Elde edilen sonuçlara göre PMMs ekstresi diğer ekstrelerden daha güçlü demir (III) iyonu indirgeme antioksidan aktivitesi gösterdiği tespit edilmiştir.

Bu çalışmadan elde edilen sonuçlara göre, metanol muamelesi ile elde edilen ekstrelerin diğer ekstrelere göre daha yüksek antioksidan aktiviteye sahip olduğu saptanmıştır. Nitekim PMMs, en yüksek DPPH radikali süpürücü $(1,087 \pm 0,06 \mathrm{mg} /$ $\mathrm{mL}$ ) ve demir (III) iyonu indirgeme gücü (IC50: 2,121 $\pm 0,001$ $\mu \mathrm{M} \mathrm{FeSO} 4 / \mathrm{mg}$ ekstre) aktivitesi göstermiştir. PMM ekstresinin ise en güçlü ABTS katyon radikali süpürücü aktiviteye (IC50: $2,11 \pm 0,19 \mathrm{mg} / \mathrm{mL}$ ) sahip olduğu tespit edilmiştir.

\section{Antimikrobiyal aktivite:}

Bitkinin ekstrelerinin klinik açıdan önemli bazı Gram pozitif, Gram negatif bakterilere ve C. albicans'a karşı gösterdikleri antimikrobiyal aktivite Tablo 2'de yer almaktadır. Bu sonuçlardan görüldüğü üzere sadece PHMs, PMMs ve PMM ekstrelerinde aktivite saptanmıştır. Ekstrelerin test edildiği mikroorganizmalar içerisinde sadece $S$. epidermidis ve $K$. pneumoniae suşlarına karşı etki gösterdikleri tespit edilmiştir. Gözlenen antimikrobiyal etkinlik S. epidermidis’e karşı daha düşük konsantrasyonda gözlenmiştir.

\section{Tartışma}

Pedicularistürleriüzerinde bugüne kadar yapılan çalışmalarda majör etken bileşik olarak iridoit ve feniletanoit bileşikleri izole edilmiştir. Pedicularis condensata türü üzerinde daha önce yapılan çalışmalarda bitkinin diğer Pedicularis türlerine benzer olarak iridoit ve feniletanoit bileşikleri taşıdığı saptanmıştır. İridoit glikozitlerinin nöroprotektif, antikanser, antienflamatuvar, immunomodülatör, antioksidan, antimikrobiyal, hipoglisemik, hipolipidemik, yara iyileştirici, koleretik, antialerjik, anksiyolitik etki ortaya koyduğu gösterilmiştir (19). Feniletanoit glikozitleri üzerinde yapılan çalışmalarda hepatoprotektif, antioksidan, sitotoksik, antienflamatuvar, a-glukozidaz inhibitör, nöroprotektif, antibakteriyal, antiviral, immunomodulatör etki gösterdiği tespit edilmiştir (20). Bu türün daha önce yapılmış anatomik incelemesine literatürde rastlanmadığından bu çalışmada anatomik yapısına da yer verilmiştir. Farklı yöntemler ile farklı çözücüler kullanılarak elde edilmiş ekstrelerinin aktivite testlerinin sonuçları sunulmuştur. Trabzon'dan toplanan bitkinin toprak üstü kısımlarından maserasyon ve Soxhlet cihazında sürekli ekstraksiyon ile elde edilen çeşitli ekstrelerin (hekzan, diklorometan, metanol ekstreleri; metanol maseratı) sahip olduğu antioksidan ve antimikrobiyal aktiviteler incelenmiştir.

PMMs ekstresinin en yüksek DPPH radikali süpürücü ve demir (III) iyonu indirgeme gücü etki gösterirken PMM ekstresinin en güçlü ABTS katyon radikali süpürücü aktiviteye sahip olduğu dikkate alındığında bitkinin içerdiği polar bileşiklerin bu aktivitede rol oynadığı düşünülmektedir. Ayrıca metanol ekstrelerinin arasında aktivite farkı olmasınnın aktivitede rol oynayan polar bileşiklerin isıda etkilenen bileşikler olmasından kaynaklandığı tahmin edilmektedir. PMM'nin de etkin 
olması ile bazı apolar bileşiklerin aktiviteye olumlu etkilerinin olduğu düşünülmektedir.

Sadece PHMs, PMMs ve PMM ekstrelerinin antimikrobiyal aktivite göstermesinden antimikrobiyal etkinliğinden sorumlu bileşiklerin sadece maserasyon ile tüketilebildiği ve Soxhlet ile elde edilen ekstrelerde bu aktivitenin görülmemesinden aktif bileşiklerin ısıda bozulduğu anlaşılmaktadır. Ayrıca ekstrelerin tüketildiği çözücüler göz önüne alındığında aktivitede çok apolar ve çok polar bileşiklerin rolü olduğu görülmüştür.

Pedicularis sibthorpii ve $P$. wilhelmsiana üzerinde yapılan bir araştırmada metanol ekstrelerinin antioksidan etkisi (DPPH yöntemi ile), total fenol ve total flavanoit içerikleri araştırılmıştır. Bitkilerin antioksidan aktiviteleri sırası ile $0,01-0,7 \mathrm{mg} / \mathrm{mL}$ ve $0,01-1,02 \mathrm{mg} / \mathrm{mL}$ aralıklarında saptanmıştır (15). Aynı merkezde bu iki türün toprak üstü kısımlarının Soxhlet cihazında sürekli ekstraksiyonu ile elde edilen n-hekzan, diklorometan ve metanol ekstrelerinin antioksidan ve antimikrobiyal aktivite testleri sonucunda metanol ekstresinin diğer ekstrelere göre daha iyi antioksidan aktiviteye sahip olduğu görülmüştür. Yine her iki türün metanol ekstreleri özellikle Staphylococcus epidermidis ve $S$. aureus gibi Gram pozitif bakterilere antibakteriyal aktivite göstermiştir. Buna karşılık hiçbir ekstrede Candida albicans üzerine etki gözlemlenmemiştir (16). Ekibimiz tarafından çalışılan $P$. condensata türünden elde edilen ekstreler; $P$. sibthorpii ve $P$. wilhelmsiana türlerinden elde edilen metanol ekstrelerinin gösterdiği kadar yüksek antioksidan aktivite göstermemiş olsa da benzer olarak, bitkiden tüketilen metanol ekstreleri diğer ekstrelerin arasında en yüksek antioksidan aktiviteyi göstermiştir. Bununla birlikte bu çalışmada Soxhlet cihazında methanol ile tüketilerek elde

\section{Anatomy and Activity Studies of Pedicularis condensata \\ ABSTRACT}

The genus Pedicularis comprises with 11 species, 2 of them are endemic, in Turkey. The Pedicularis species are known as "sormuk, sorma, sormuk otu". Its usage is not well known in folk medicine, though the usage as food because of its nectar is recorded in East-Anatolia. According to the published studies on Pedicularis condensata Bieb. till today, it is seen that this plant takes a place in patent, taken during the hair dye studies. Additionally, various investigations on the isolation and activity of Pedicularis (Kesgerotu) species are reported in literature. According to these, the Pedicularis species contain iridoids and phenylethanoid compounds as major components. It has demonstrated that, the iridoids has antioxidant, antimicrobial, antiinflamatory, immunomodulator activities etc. and the edilen ekstrede Khodaie ve ark. (16) tarafından aynı türler üzerinde yapılan devam çalışmasındakine benzer antioksidan aktivite belirlenmiş ve farklı olarak metanol ekstresi yanı sıra hekzan ekstresi de antimikrobiyal aktivite göstermiştir.

Aktivite çalışmalarının dışında 3 Pedicularis türü ( $P$. condensata, P. sibthorpii Boiss. ve $P$. wilhelmsiana Fisch ex. M. Bieb.) ile yapılan bir izolasyon araştırması ile bu türlerden feniletanoit glikozitleri izole edilerek yapıları tayin edilmiştir. P. condensata'dan verbaskozit ve 2'-o-asetilverbaskozit bileşikleri izole edilmiştir (14). Akdemir ve ark., P. condensata türünün toprak üstü kısımlarına ait metanol ekstresinden bir yeni iridoit bileşiği (6-O-asetilokubin) dışında 5 bilinen iridoit (okubin, 8-epiloganin, mussenozit, şanzizit metil esteri); 2 feniletanoit glikozitleri (verbaskozit ve ekinakozit) izole etmişlerdir (18). Bu izolasyon çalışmalarından anlaşıldığ üzere Pedicularis condensata başlıca iridoit ve feniletanoit glikozitleri taşımaktadır. Bu türün gösterdiği aktivitelerin taşıdığı bileşiklerden ileri geldiği tahmin edilmektedir. Nitekim izole bileşikler ile yapılan aktivite çalışmaları ile okubin, 8-O- trans-sinnamoil şanzizit metil esteri, 6,9-epi-8$O$-asetilşanzizit metil esteri, 8-O-trans-sinnamoilmussenozit, 8-O-kafeoilmussenozit ve verbaskozit bileşikleri ve bazı verbaskozit türevlerinin antioksidan; okubin, şanzizit metil esteri ve verbaskozit bileşiklerinin antimikrobiyal aktivitelerinin bulunduğu ortaya konmuştur (19, 27-30).

Günümüzde artık farmakognozik araştırmalar aktivite yönlendirmeli izolasyon çalışmaları şeklinde gerçekleştirilmektedir. Tüm bu sonuçlar ışı̆̆ında; ekstrelerin diğer aktiviteler açısından incelenmesinin devam edilmesi gerektiği ve bu çalışmalarla elde edilecek verilere göre taşıdığ bileşiklerin aktivite tayinlerinin yapılmasının yararlı olacağ düşünülmektedir.

phenylethanoid compounds show antioxidant, antibacterial, antiviral as well as antiinflamatory, hepatoprotective activities etc. In view of the isolation studies, it is possible that Pedicularis condensata shows some of these activities. The anatomical and activity studies on this species were not done. In this paper, an anatomical study and the results of activity tests of the extracts, which were obtained using various methods and different solvents, were presented. The antioxidant and antimicrobial activities, possessed by various extracts (hexane, dichloromethane, methanol and methanol macerate), which were prepared from the aerial parts (collected in Trabzon) by maceration and Soxhlet extraction, were investigated.

Keywords: Pedicularis condensata, plant anatomy, antimicrobial, antioxidant 


\section{Kaynaklar}

1. Flora of Turkey and the East Aegean Islands, Vol. 6. Editor : Davis PH. Edinburgh University Press, Edinburgh. 1978.

2. Güner A, Aslan S, Ekim T, Vural M, Babaç MT. (Edlr.). Türkiye Bitkileri Listesi (Damarlı Bitkiler). Nezahat Gökyiğit Botanik Bahçesi ve Flora Araştırmaları Derneği Yayını, İstanbul. 2012.

3. Altundağ E. Iğdır İlinin (Doğu Anadolu Bölgesi) Doğal Bitkilerinin Halk Tarafından Kullanımı. İstanbul Üniversitesi, Sağlık Bilimleri Enstitüsü, Farmasötik Botanik Anabilim Dalı, Doktora Tezi, 2009, İstanbul.

4. Tuzlacı E. Türkiye Bitkileri Sözlüğü. Alfa Yayınları, İstanbul. 2006.

5. Yuan C-S, Sun X-B, Zhao P-H, Cao M-A. Antibacterial constituents from Pedicularis armata. J Asian Nat Prod Res 2007; 9: 673-7.

6. Berg T, Damtoft S, Rosendal Jensen S, Nielsen BJ, Rickelt LF. Iridoid glucosides from Pedicularis. Phytochem 1985; 24: 4913.

7. Yuan C-S, Zhang Q, Xie W-D, Yang X-P, Jia Z-J. Iridoids from Pedicularis kansuensis forma albiflora. Pharmazie 2003; 58: 428-30.

8. Zhang B-B, Shi K, Liao Z-X, Dai Y, Zou Z-H. Phenylpropanoid glycosides and triterpenoid of Pedicularis kansuensis Maxim. Fitoterapia 2011; 82: 854-60.

9. Zhang Z-X, Xie W-D, Jia Z-J. Glycosides from two Pedicularis species. Biochem Syst Ecol 2008; 36: 467-72.

10. Jiang T-F, Ou Q-Y, Shi Y-P. Seperation and determination of phenylpropanoid glycosides from Pedicularis species by capilary electrophoresis. J Chromatogr A 2003; 986: 163-7.

11. Li J, Ge R-C, Zheng R-L, Liu Z-M, Jia Z-J. Antioxidative and chelating activities of phenylpropanoid glycosides from Pedicularis striata. Zhongguo Yao Li Xue Bao 1997; 18: 77-80.

12. Li J, Zheng R-L, Liu Z-M, Jia Z-J. Scavenging efects of phenylpropanoid glycosides on superoxide and its antioxidation effect. Zhongguo Yao Li Xue Bao 1992; 13: 42730 .

13. Wang P, Kang J, Zheng R, Yang Z, Lu J, Gao J, Jia Z. Scavenging Effects of Phenylpropanoid Glycosides from Pedicukk on Superoxide Anion and Hydroxyl Radical by the Spin Trapping Method (95) 02255-4. Biochem Pharmacol 1996; 51: 687-91.

14. Eribekyan MI, Agababyan EY, Arutyunyan LS. Phenylpropanoids Glycosides of Pedicularis condensata, $P$. wilhelmsiana and P. sibthorpii. Khim Prir Soedin 1991; 5: 7234.

15. Khodaie L, Bamdad S, Delazar A, Mazemiyeh H. Antioxidant, Total Phenol and Flavonoid Contents of Two Pedicularis L. Species from Eastern Azerbaijan, Iran. BioImpacts 2012; 2: 47-53.

16. Khodaie L, Delazar A, Lotfipour F, Nazemiyeh H. Antioxidant and Antimicrobial activity of Pedicularis sibthorpii Boiss. and Pedicularis wilhelmsiana Fisch ex. Adv Pharm Bull 2012; 2: 8992.
17. Khodaie L, Delazar A, Lotfipour F, Nazemiyeh H, Asnaashari S, Moghadam SB, Nahar L, Sarker SD. Phytochemistry and bioactivity of Pedicularis sibthorpii growing in Iran. Rev Bras Farmacogn 2012; 22: 1268-75.

18. Akdemir Z, Çalış İ, Junoir P. Iridoid and phenylpropanoid glycosides from Pedicularis condensata. Phytochem 1991; 30: 2401-2.

19. Tundis R, Loizzo MR, Menichini F, Statti GA, Menichini F. Biological and pharmacological activities of Iridoids: Recent developments. Mini Rev Med Chem 2008; 8: 399-420.

20. Xue Z, Yang B. Phenylethanoid glycosides: Research advances in their phytochemistry, pharmacological activity and pharmacokinetics. Molecules 2016; 21: 991.

21. Balkan IA, Taşkın T, Doğan HT, Deniz I, Akaydın G, Yeşilada E. A comparative investigation on the in vitro antiinflammatory, antioxidant and antimicrobial potentials of subextracts from the aerial parts of Daphne oleoides Schreb. subsp. oleoides. Ind Crops Prod 2016; 95: 695-703.

22. Re R, Pellegrini N, Proteggente A, Pannala A, Yang M, RiceEvans C. Antioxidant activity applying an improved ABTS radical cation decolorization assay. Free Radic Biol Med 1999; 26: 1231-7.

23. Benzie IF, Strain JJ. The ferric reducing ability of plasma (FRAP) as a measure of "antioxidant power": the FRAP assay. Anal Biochem 1996; 239: 70-6.

24. Clinical and Laboratory Standards Institute (CLSI). Methods for dilution antimicrobial susceptibility tests for bacteria that grow aerobically: Approved Standard M7-A5. Wayne, PA: CLSI. 2006.

25. Clinical and Laboratory Standards Institute (CLSI). Reference Method for Broth Dilution Antifungal Susceptibility Testing of Yeasts; Approved Standard-Third Edition. M27 -A3. Wayne, PA: CLSI. 2008.

26. Iqbal E, Abu Salim K, Lim LBL. Phytochemical screening, total phenolics and antioxidant activities of bark and leaf extracts of Goniothalamus velutinus (Airy Shaw) from Brunei Darussalam. J King Saud Univ Sci 2015; 27: 224-32.

27. Shim KM, Choi SH, Jeong MJ, Kang SS. Effects of Aucubin on the healing of oral wounds. In Vivo 2007; 21: 1037-41.

28. Jin L, Xue H-Y, Jin L-J, Li S-Y, Xu Y-P. Antioxidant and pancreasprotective effect of aucubin on rats with streptozotocininduced diabetes. Eur J Pharmacol 2008; 582: 162-7.

29. Shahzadi T, Abbasi MA, Ur-Rehman A, Riaz T, Khan KM, Ashraf M, Afzal, Akhtar MN, Ajaib M. Antioxidant and Lipoxygenase Inhibiting New Iridoid Glucosides from Caryopteris odorata. Nat Prod Res 2013; 27: 302-13.

30. Ndjateu FST, Tsafack RBN, Nganou BK, Awouafack MD, Wabo HK, Tene M, Tane P, Eloff JN. Antimicrobial and Antioxidant Activities of Extracts and Ten Compounds from Three Cameroonian Medicinal Plants: Dissotis perkinsiae (Melastomaceae), Adenocarpus mannii (Fabaceae) and Barteria fistulosa (Passifloraceae). S Afr J Bot 2014; 91: 37-42. 